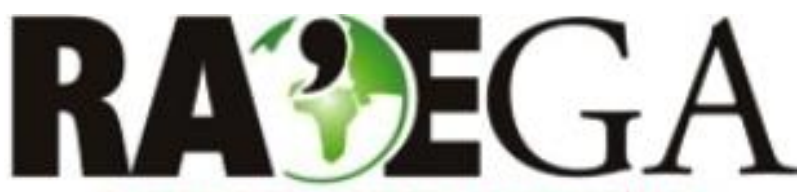

O ESPACYO GEOGRÁFICO EM ANÁLISE

\title{
UMA ABORDAGEM INICIAL SOBRE OS CONCEITOS DE GEODIVERSIDADE, GEOCONSERVAÇÃO E PATRIMÔNIO GEOMORFOLÓGICO
}

\section{INITIAL APPROACH ABOUT GEODIVERSITY, GEOCONSERVATION AND GEOMORPHOLOGICAL HERITAGE}

\author{
Paula Cristina Almeida de Oliveira \\ Doutoranda em Geografia pela Universidade Federal \\ de Uberlândia - UFU \\ Bolsista CAPES \\ Uberlândia, MG, Brasil \\ e-mail: paulacristinageo@gmail.com \\ António de Sousa Pedrosa \\ Professor Adjunto do Instituto de Geografia da Universidade Federal \\ de Uberlândia - UFU \\ Uberlândia, MG, Brasil \\ e-mail: aspedros@gmail.com \\ Silvio Carlos Rodrigues \\ Professor Associado do Instituto de Geografia da Universidade \\ Federal de Uberlândia - UFU \\ Uberlândia, MG, Brasil \\ e-mail: silgel@ufu.br
}

Artigo recebido em: 03/02/2012.

Artigo aceito em: 05/11/2013.

\section{Resumo}

Apesar de o Brasil ser um país rico em geodiversidade existe uma carência de estudos e metodologias de inventariação e quantificação tanto sobre a geodiversidade quanto do patrimônio geomorfológico e da geoconservação. Nesse sentido, este trabalho tem como objetivo fazer uma revisão sobre os conceitos de Geodiversidade, Patrimônio Geomorfológico e Geoconservação e discutir sobre a difusão e os caminhos a serem seguidos por esse tipo de estudo no Brasil. A metodologia utilizada envolveu uma ampla revisão bibliográfica pertinente à temática (livros, dissertações, teses e artigos) como, por exemplo, os trabalhos de Stanley (2000); Gray (2005); Brilha (2005); Pereira (2006), dentre outros. 
Palavras-chave: geodiversidade, patrimônio geomorfológico, geoconservação.

\begin{abstract}
Although Brazil is a country rich in geodiversity there is a lack of studies and methodologies for inventorying and quantifying both on geodiversity as geomorphological heritage and geoconservation. Thus, this paper aims to review the concepts of Geodiversity, Geomorphological Heritage and Geoconservation and discuss the diffusion and the paths to be followed for this type of study in Brazil. The methodology involved an extensive literature review relevant to the subject (books, dissertations, thesis and articles), for example, the works by Stanley (2000); Gray (2005); Brilha (2005); Pereira (2006), among others.
\end{abstract}

Keywords: geodiversity, geomorphological heritage, geoconservation.

\title{
INTRODUÇÃO
}

O Brasil é um país rico em geodiversidade, fato que se deve à sua grande extensão territorial e sua diversidade geológica. No entanto, a carência de estudos e metodologias de inventariação e quantificação dessa geodiversidade atuam como entrave para que estratégias e programas de proteção, valorização e conservação sejam criadas, tanto pela esfera pública ou privada.

O patrimônio geomorfológico, sendo considerado produto da geodiversidade (assim como o patrimônio geológico, mineralógico, paleontológico, etc.) é constantemente modificado pela ação antrópica. Serras, planaltos, planícies fluviais, rios, são por vezes alterados/destruídos para a construção de empreendimentos como estradas, linhas férreas, pavimentação de ruas, expansão de áreas agricultáveis, etc. Nesse sentido, a geoconservação atua como uma ferramenta de apoio, que auxilia na proteção e no uso sustentável dos elementos da geodiversidade.

No cenário mundial, várias são as iniciativas referentes à geoconservação, como leis específicas de proteção, associações, projetos integrados entre países, etc. No cenário nacional, porém, as iniciativas são pontuais, muitas das vezes relacionadas à conservação da biodiversidade.

$\mathrm{Na}$ esfera pública, os trabalhos sobre a temática estão ligados, em sua maioria, a dissertações de mestrado, teses de doutorado e projetos desenvolvidos pelo 
Serviço Geológico Brasileiro (CPRM) e serviços geológicos regionais como: Projeto Caminhos Geológicos - Serviço Geológico do Rio de Janeiro; Projeto Monumentos Geológicos do Rio Grande do Norte; Projeto Monumentos Geológicos de São Paulo; Projeto Caminhos Geológicos da Bahia; Projeto de Sítios Geológicos e Paleontológicos do Estado do Paraná.

O objetivo desse artigo é fazer uma revisão sobre os conceitos de geodiversidade, geoconservação e patrimônio geomorfológico, apontando exemplos relativos a escalas de abordagem, iniciativas nacionais e internacionais de geoconservação, valoração de geomorfossítios e dificuldades de abordagens.

\section{CONSIDERAÇÕES SOBRE A GEODIVERSIDADE}

Geodiversidade pode ser definida como a "variação natural (diversidade) de aspectos geológicos (rochas, minerais, fósseis), geomorfológicos (formas da Terra, processos físicos) e de solo. Inclui suas composições, relações, propriedades, interpretações e sistemas". (GRAY, 2004 apud GRAY, 2005, p.5).

Em outras palavras, a geodiversidade compreende a diversidade geológica (aspectos abióticos) incluindo não somente os testemunhos derivados de um passado geológico, como o caso dos minerais, rochas e fósseis (Figura 1), como também aqueles processos atuais que darão origem a novos testemunhos (mudanças na paisagem, variação do nível dos oceanos, sedimentação, etc.). (BRILHA, 2005; ProGEO,2011; RODRIGUES e PEDROSA, 2013).

Esse termo passou a ser amplamente difundido por ocasião da Conferência de Malvern sobre a Conservação Geológica e Paisagística, realizada em 1993, no Reino Unido, e vem ganhando ênfase ao longo dos anos com a publicação de livros, artigos científicos e trabalhos envolvendo a comunidade científica mundial (NASCIMENTO; RUCHKYS; MANTESSO-NETO, 2008).

Apesar dos esforços na divulgação dessa temática, existe certo desconhecimento ao se tratar de geodiversidade, principalmente pela falta de divulgação do seu significado, seja pela sociedade em geral, pelo poder público e privado, e até mesmo pela comunidade científica. A geodiversidade é tão importante quanto a biodiversidade, pois, sendo ambas inter-relacionadas e componentes do 
sistema (vivo e não vivo), têm a mesma importância para o planeta, e sendo abordadas em conjunto, as ações para conservação serão mais efetivas.

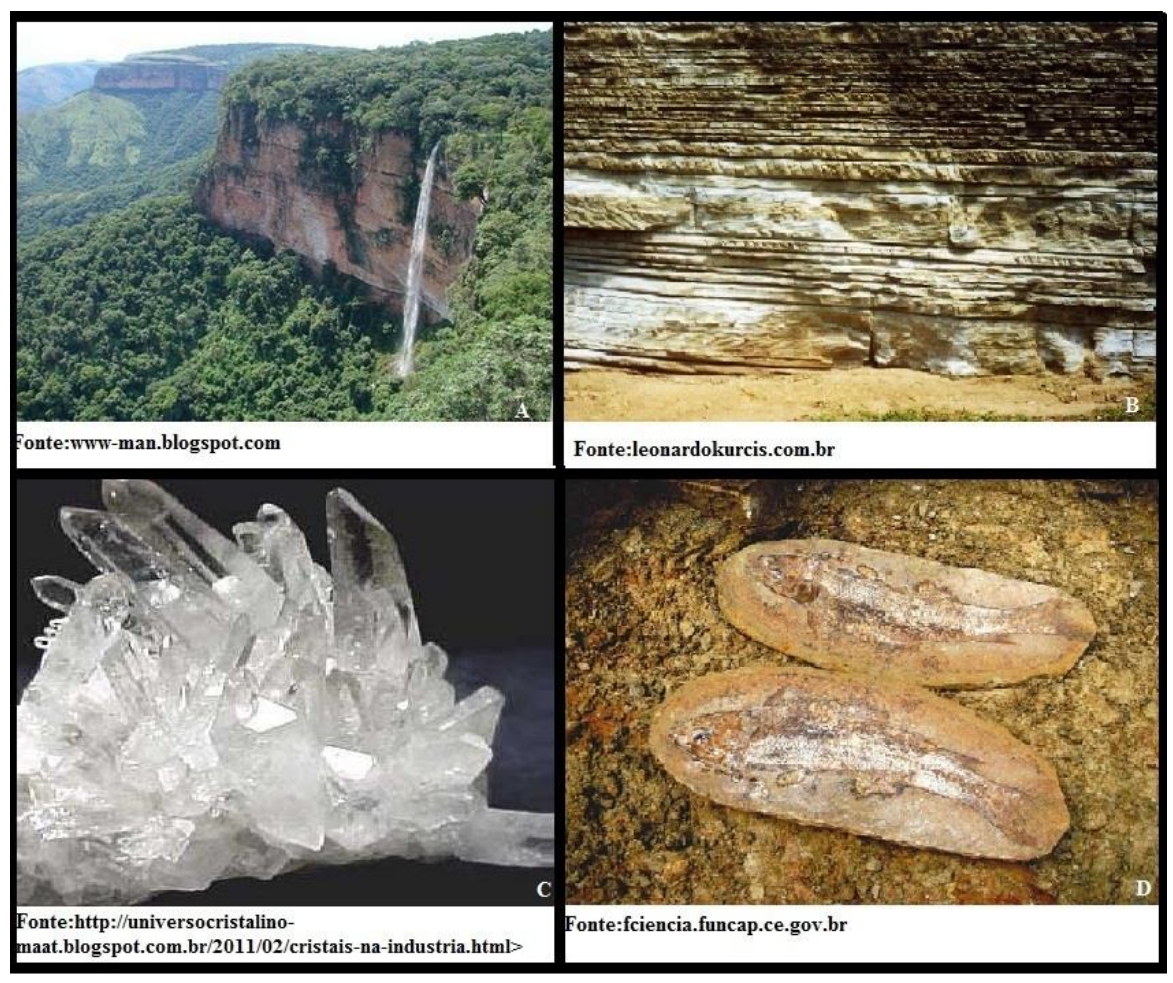

Figura 1 - Mosaico de elementos da geodiversidade. A: Chapada dos Guimarães; B: Paredão de varvito em Itu; C: cristais de Quartzo; D: fóssil de peixe do Cretáceo da Bacia do Araripe. Organização dos autores.

A geodiversidade vai além dos recursos abióticos do planeta, consiste também na ligação entre pessoas, paisagens e suas culturas, segundo Stanley (2000, p.15) "pela interação da biodiversidade com solos, minerais, rochas, fósseis, processos ativos e o meio ambiente construído". Nesse sentido, o planeta Terra apresenta uma grande variedade tanto na biodiversidade quanto na geodiversidade, que a cada dia se transformam e se modificam de forma natural, e também pela ação antrópica, como por exemplo, a mineração predatória, a construção de barragens, hidrelétricas, rodovias, disposição de resíduos sólidos urbanos e industriais, vandalismo, depredação, entre outras. (BORBA, 2011, p.7).

As escalas de abordagens sobre o tema da geodiversidade são múltiplas, variando entre escalas nacionais e regionais (Pereira et al, 2013; Hjort e Luoto, 2010; Ruban, 2010 e 2011; Lima, Brilha e Salamuni, 2010; Leman, Reedman e Pei, 2008), bem como pode ser feitas a nível de detalhe (Burek, 2012; Rodrigues e Silva, 2012; Bento e Rodrigues, 2011.) 
Dessa forma, a proteção e conservação da geodiversidade são de extrema importância, e se justificam porque a ela são atribuídos valores, sejam econômicos, culturais, sentimentais ou outros (BRILHA, 2005, p.32). Ainda nesta temática Perkins (2010) e Bento e Rodrigues (2013) apontam que a necessidade de conservar a natureza advém de sentimentos de cuidados e proteção com a mesma, em função de um claro reconhecimento do valor intrínseco da natureza, bem como de um senso pessoal de responsabilidade de proteção contra riscos e prejuízos advindos de externalidades.

Gray (2005) destaca e exemplifica alguns valores que podem ser atribuídos para a geodiversidade, demonstrados no Quadro 1.

Incorporando os valores dados ao conceito, o Serviço Geológico do Brasil (CRPM) definiu geodiversidade de uma forma mais ampla, como sendo:

\begin{abstract}
natureza abiótica (meio físico) constituída por uma variedade de ambientes, fenômenos e processos geológicos que dão origem às paisagens, rochas, minerais, solos, águas, fósseis e outros depósitos superficiais que propiciam o desenvolvimento da vida na Terra, tendo como valores intrínsecos a cultura, o estético, o econômico, o científico, o educativo e o turístico. (CPRM, 2006, s/p, apud LOPES e ARAÚJO, 2011, p.69)
\end{abstract}

Notadamente, os impactos da ação antrópica são um dos maiores responsáveis pela perda da geodiversidade mundial, seja em micro ou macro escala, principalmente em virtude das necessidades da sociedade.

A perda de geodiversidade pode ser geralmente bem definida, se entendermos a mesma como uma diminuição no número de tipos de geossítios em determinada região, geralmente associada a danos causados por modificações de origem externa (Ruban, 2010). Seguindo esta premissa o mesmo autor apresenta conceitos como Geoabundância, definida como a quantidade total de geossítios de um determinado território e o de Georriqueza que envolve a quantidade de geossítios, onde cada tipologia de geossítios ocorre como elemento de um conjunto complexo ou de forma simples. (RUBAN, 2010; RODRIGUES; SILVA, 2012; RODRIGUES; PEDROSA, 2013). Estes conceitos podem ser utilizados para a avaliação da perda ou ganho de geodiversidade em regiões afetadas, por exemplo, por grandes empreendimentos. 
Quadro 1 - Valores da geodiversidade. Adaptado de Gray, 2005. Organização dos autores.

\begin{tabular}{|c|c|c|c|}
\hline \multirow{2}{*}{$\begin{array}{l}\quad \text { Valor } \\
\text { Valor } \\
\text { Intrínseco }\end{array}$} & Definição & \multicolumn{2}{|c|}{ Exemplos } \\
\hline & $\begin{array}{l}\text { valor próprio da natureza, } \\
\text { independente da valoração } \\
\text { atribuída pela sociedade. }\end{array}$ & 1 - Valor intrínseco & $\begin{array}{l}\text { Natureza abiótica livre de } \\
\text { valorações humanas }\end{array}$ \\
\hline \multirow{4}{*}{$\begin{array}{l}\text { Valor } \\
\text { Cultural }\end{array}$} & \multirow{4}{*}{$\begin{array}{l}\text { É atribuído pela sociedade, } \\
\text { quando existe uma relação } \\
\text { social, cultural, religiosa com o } \\
\text { meio físico que o rodeia, como } \\
\text { por exemplo, questões ligadas } \\
\text { a arqueologia, folclore, } \\
\text { religião, geomorfologia }\end{array}$} & 2 - Folclore & "Devils Tower" \\
\hline & & $\begin{array}{l}3 \text { - } \\
\text { Histórico/Arqueológico }\end{array}$ & "Alibates Flint Quarries" \\
\hline & & 4 - Espiritual & "Chief Mountain" \\
\hline & & $\begin{array}{l}5 \text { - Sensação de } \\
\text { pertencimento }\end{array}$ & John Muir em Yosemite \\
\hline \multirow[t]{6}{*}{$\begin{array}{l}\text { Valor } \\
\text { Estético }\end{array}$} & \multirow{6}{*}{$\begin{array}{l}\text { É um valor relacionado ao } \\
\text { impacto que é causado aos } \\
\text { sentidos. }\end{array}$} & 6 - Paisagens locais & $\begin{array}{l}\text { Vistas do mar, sons de } \\
\text { ondas, toque de areia }\end{array}$ \\
\hline & & 7 - Geoturismo & Grand Canyon; Yellowstone \\
\hline & & 8 - Atividades de lazer & $\begin{array}{l}\text { Montanhismo, exploração } \\
\text { de caverna, }\end{array}$ \\
\hline & & $\begin{array}{l}9 \text { - Apreciação via } \\
\text { meios de comunicação }\end{array}$ & $\begin{array}{l}\text { Documentários sobre a } \\
\text { natureza }\end{array}$ \\
\hline & & $\begin{array}{l}10 \text { - Atividades } \\
\text { voluntárias }\end{array}$ & $\begin{array}{l}\text { Construção de caminhos, } \\
\text { restauração de minas }\end{array}$ \\
\hline & & 11 - Inspiração artística & Pinturas \\
\hline \multirow{7}{*}{$\begin{array}{l}\text { Valor } \\
\text { Económico }\end{array}$} & \multirow{7}{*}{$\begin{array}{l}\text { É um valor baseado na } \\
\text { dependência da sociedade em } \\
\text { relação aos elementos da } \\
\text { geodiversidade, sendo mais } \\
\text { compreensível e objetivo. São } \\
\text { exemplos, a dependência do } \\
\text { homem pelos combustíveis } \\
\text { fósseis, materiais geológicos } \\
\text { para construção civil, aguas } \\
\text { subterrâneas, etc. }\end{array}$} & 12 - Energia & Carvão; Petróleo \\
\hline & & 13 - Minerais industriais & Potássio; Caulinita; etc \\
\hline & & 14 - Minerais metálicos & $\begin{array}{l}\text { Ferro; prata; zinco; ouro; } \\
\text { etc. }\end{array}$ \\
\hline & & $\begin{array}{l}15 \text { - Minerais de } \\
\text { construção }\end{array}$ & $\begin{array}{l}\text { Rocha; agregados; } \\
\text { calcários; betumes }\end{array}$ \\
\hline & & 16 - Gemas & Diamantes; Safiras; etc. \\
\hline & & 17 - Fósseis & $\begin{array}{l}\text { Tiranossauros; lojas de } \\
\text { fósseis e minerais }\end{array}$ \\
\hline & & 18 - Solo & $\begin{array}{l}\text { Produção de alimentos; } \\
\text { madeira; etc. }\end{array}$ \\
\hline \multirow[t]{8}{*}{$\begin{array}{l}\text { Valor } \\
\text { Funcional }\end{array}$} & \multirow{8}{*}{$\begin{array}{l}\text { Refere-se ao valor da } \\
\text { geodiversidade que está: a) } \\
\text { em seu local de origem e } \\
\text { possui caráter utilitário para o } \\
\text { homem e b) enquanto base } \\
\text { para a sustentação de } \\
\text { sistemas físicos e ecológicos } \\
\text { na superfície da Terra. }\end{array}$} & 19 - Plataformas & $\begin{array}{l}\text { Infraestruturas e construção } \\
\text { em terra }\end{array}$ \\
\hline & & $\begin{array}{l}20 \text { - Armazenamento e } \\
\text { reciclagem }\end{array}$ & $\begin{array}{l}\text { Armazenamento de } \mathrm{CO}_{2} \\
\text { aquíferos }\end{array}$ \\
\hline & & 21 - Saúde & $\begin{array}{l}\text { Nutrientes e minerais; } \\
\text { paisagens terapêuticas. }\end{array}$ \\
\hline & & 22 - Aterros & $\begin{array}{l}\text { Aterro humano, câmeras de } \\
\text { lixo atômico }\end{array}$ \\
\hline & & $\begin{array}{l}23 \text { - Controle de } \\
\text { poluição }\end{array}$ & $\begin{array}{l}\text { Solo e rocha como filtros de } \\
\text { água }\end{array}$ \\
\hline & & 24 - Química da água & $\begin{array}{l}\text { Água mineral, whisky, } \\
\text { cerveja }\end{array}$ \\
\hline & & 25 - Funções do solo & $\begin{array}{l}\text { Agricultura, horticultura, } \\
\text { viticultura, florestamento }\end{array}$ \\
\hline & & $\begin{array}{l}26 \text { - Funções do } \\
\text { geossistema }\end{array}$ & $\begin{array}{l}\text { Processos costeiros, } \\
\text { fluviais, glaciais }\end{array}$ \\
\hline \multirow{4}{*}{$\begin{array}{l}\text { Valor } \\
\text { Científico e } \\
\text { educativo }\end{array}$} & \multirow{4}{*}{$\begin{array}{l}\text { Refere-se à importância dos } \\
\text { elementos da geodiversidade } \\
\text { para a investigação científica e } \\
\text { para a educação. }\end{array}$} & 28 - Pesquisa científica & $\begin{array}{l}\text { História da terra, evolução } \\
\text { geoprocessos }\end{array}$ \\
\hline & & $\begin{array}{l}29 \text { - História da } \\
\text { pesquisa }\end{array}$ & $\begin{array}{l}\text { Identificação de } \\
\text { desconformidades; etc. }\end{array}$ \\
\hline & & $\begin{array}{l}30 \text { - Monitoramento } \\
\text { ambiental }\end{array}$ & $\begin{array}{l}\text { Mudança de clima, } \\
\text { mudança do nível do mar, } \\
\text { poluição }\end{array}$ \\
\hline & & $\begin{array}{l}31 \text { - Educação e } \\
\text { treinamento }\end{array}$ & $\begin{array}{l}\text { Estudos de campo, } \\
\text { treinamento especializado. }\end{array}$ \\
\hline
\end{tabular}




\title{
DEFINIÇÕES E METODOLOGIAS ACERCA DO PATRIMÔNIO GEOMORFOLÓGICO
}

No panorama mundial, os estudos referentes ao patrimônio natural são bem recentes, ganhando mais destaque depois da publicação do documento da Convenção para a proteção do Patrimônio Mundial, Cultural e Natural da Organização das Nações Unidas para a Educação, a Ciência e a Cultura (UNESCO), de 1972, em que foram considerados patrimônios naturais:

\begin{abstract}
os monumentos naturais constituídos por formações físicas e biológicas ou por conjuntos de formações de valor universal excepcional do ponto de vista estético ou científico; as formações geológicas e fisiográficas, e as zonas estritamente delimitadas que constituam habitat de espécies animais e vegetais ameaçadas de valor universal excepcional do ponto de vista estético ou científico; os sítios naturais ou as áreas naturais estritamente delimitadas detentoras de valor universal excepcional do ponto de vista da ciência, da conservação ou da beleza natural. (UNESCO, 1972, p. 3)
\end{abstract}

Nesse âmbito do patrimônio natural, insere-se o patrimônio geológico, que engloba os locais e objetos especiais (rochas, afloramentos, paisagens, etc.) que auxiliam na compreensão da história da Terra. (ProGEO, 2011).

Para Brilha (2005), o patrimônio geológico é entendido como o conjunto de geossítios inventariados e caracterizados numa determinada área ou região e "integra todos os elementos notáveis que constituem a geodiversidade, incluindo o patrimônio paleontológico, o patrimônio mineralógico, o patrimônio geomorfológico, o patrimônio hidrogeológico entre outros”. (BRILHA 2005, p.54).

Eberhardt (1997 apud Sharples, 2002) definiu o patrimônio geológico ou geopatrimônio como aquele constituído por "componentes da geodiversidade importantes para a humanidade por razões outras que não a extração de recursos, e cuja preservação é desejável para as atuais e futuras gerações." (BORBA, 2011, p.6).

Dentro do contexto do geopatrimônio, o patrimônio geomorfológico é que, segundo Rodrigues e Fonseca (2008) abrange os depósitos correlativos da evolução passada e presente do relevo, atualmente existentes na superfície terrestre. Pereira 
(2006) define o patrimônio geomorfológico como o conjunto de locais de interesse geomorfológico aos quais foram atribuídos um ou mais tipos de valor.

Panizza (2001) denomina de geomorfossítio as formas de relevo a que um determinado valor pode ser atribuído. Os geomorfossítios podem ser tanto individuais, quanto paisagens mais amplas, como pode ser visualizado na Figura 2.

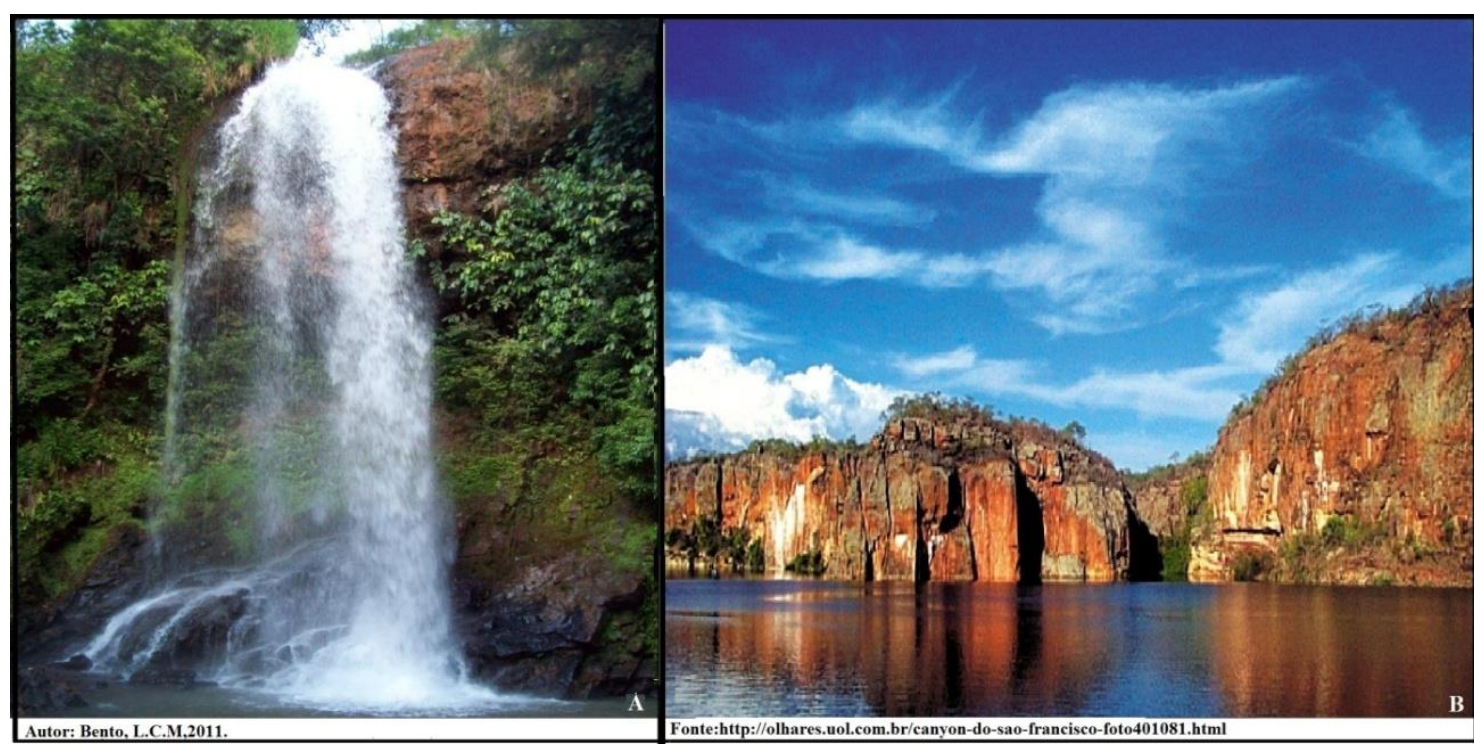

Figura 2 - Mosaico de geomorfossítios; 1: Salto Santo Antônio em Indianópolis -MG; 2: Canyon do rio São Francisco. Organização dos autores.

Para Pereira (2006, p. 34), os locais de interesse geomorfológico (ou geomorfossítios) "são vistos como elementos da cultura e potenciadores de atividades ligadas à educação ambiental ou ao geoturismo". Ainda, Vieira e Cunha (2006) afirmam que:

pelas características que 0 definem, o patrimônio geomorfológico, constitui, dentro do conjunto do patrimônio natural, um grupo bastante vulnerável, porque constitui a base sobre a qual se desenvolvem as actividades humanas e, também, porque se tem vindo a revelar como bastante atractivo para actividades de lazer, turismo, tendo despertado no seio da comunidade científica, um elevado interesse. (VIEIRA; CUNHA 2006, p.147).

Além da importância cênica, os geomorfossítios são registros da história do planeta, motivo pelo qual devem ser resguardados da ação antrópica acelerada. Sua proteção e conservação fazem parte de várias estratégias de geoconservação. 
No cenário mundial, o tema patrimônio geomorfológico vem sendo estudado desde meados da década de 1980, em países como Suíça, Itália, Portugal, França e Espanha, através de metodologias diferentes, porém todas com intuito de trazer à tona a importância dos elementos geomorfológicos, tanto para a preservação da paisagem quanto para o potencial turístico dessas áreas. Dentro desse contexto, em 2001, foi criado dentro da International Association of Geomorphologists (IAG), um grupo de trabalho chamado "geomorphosites", cujo principal objetivo é ampliar a investigação, o conhecimento e a divulgação dos locais de interesse geomorfológicos , dando ênfase na educação, conservação e atratividade do turismo em relação a esses geomorfossítios. (REYNARD; CORATZA, [20--]).

Para a avaliação do patrimônio geológico e geomorfológico, foram desenvolvidas varias metodologias, apresentadas resumidamente a seguir.

Grandgirard (1995, 1996 apud PEREIRA, 2006), desenvolveu uma metodologia que diz respeito apenas ao valor científico dos locais de interesse geomorfológico, considerando apenas dois tipos de critérios, um principal e outro secundário, respectivamente: os fatores (integridade, presença de outros tipos de geótopos, representatividade, raridade, valor paleogeográfico e existência de conhecimento científico sobre o local) e os indicadores (dimensão e configuração geométrica, constituição, perturbação funcional, idade, geodiversidade, associação, número e distribuição de formas, contexto ambiental e atividade morfogenética).

Para os fatores é conferida uma pontuação de 0 a 3 , justificadas por um pequeno texto. Para a pontuação final de cada local de interesse geomorfológico são permitidas várias possibilidades, desde média, soma, ponderações ou multiplicação das pontuações atribuídas na avaliação de cada fator.

Panizza apresentou sua metodologia em meados da década de 1990 e utilizou-a também em trabalhos posteriores. Consiste em um método simplificado para avaliar o valor científico dos locais de interesse geomorfológico, onde apenas a qualidade científica da geoforma é considerada, através da análise do seu valor científico intrínseco e do seu grau de preservação. A ponderação atribuída a cada um destes critérios depende da relevância do local de interesse geomorfológico (sem interesse ou com interesse local, regional, supra-regional e mundial) (PEREIRA, 2006). 
A metodologia de Rivas et al. (1997) é uma das mais antigas no que se refere aos geomorfossítios, sendo elaborada com objetivo de se definir indicadores para serem utilizados na avaliação de impactos ambientais sobre as geoformas. Foram definidos onze parâmetros para a quantificação, para tornar o processo de avaliação mais objetivo e quantitativo, onde os geomorfossítios de interesse são definidos com base nos valores científicos, educacionais e recreativos, e o parâmetro mais importante é representado pelo estado de conservação (PEREIRA, 2010).

Essa metodologia, apesar de ser aplicável a diversos contextos, acaba sendo restrita por ter sido concebida para um cenário específico de avaliações de impacto ambiental.

Serrano e González-Trueba (2005) desenvolveram sua metodologia baseada na utilização da cartografia geomorfológica para identificar as geoformas e interpretar a evolução geomorfológica. A partir da cartografação e do conhecimento da região são selecionados locais de interesse geomorfológico, onde cada local possui uma ficha descritiva com dados como: identificação, localização, descrição, gênese, dinâmica, cronologia, interesses principal e secundário das geoformas, e com os seus usos atuais.

São considerados os valores intrínseco ou científico; cultural ou adicional; de uso ou gestão, onde a cada um dos critérios é atribuída uma pontuação, porém existem poucos indicadores com pontuação fixa e não é referido o modo de obtenção dos valores finais. Segundo esta metodologia, os diferentes locais devem ser comparados pelos diferentes tipos de valor. Assim sendo, um local com grande valor científico pode ter pouco valor de uso, aspecto que deve estar expresso na avaliação (PEREIRA, 2006).

A proposta de Pereira (2006) para a avaliação do patrimônio geomorfológico pode ser utilizada em áreas de qualquer dimensão, baseada principalmente no conhecimento geomorfológico da área em questão. Essa proposta é subdividida em duas etapas principais: a inventariação (identificação dos potenciais locais de interesse geomorfológico; avaliação qualitativa; seleção dos locais de interesse geomorfológico; caracterização dos locais de interesse geomorfológico) e a quantificação (avaliação numérica e seriação). Para a avaliação do Patrimônio 
Geomorfológico, Pereira (2006), define cinco valores fundamentais: o cientifico, o ecológico, o cultural, o estético e o econômico, exemplificados no quadro abaixo:

Quadro 2: Valores do Patrimônio Geomorfológico. Adaptado de Pereira, 2006. Organização dos autores.

\begin{tabular}{|c|c|}
\hline $\begin{array}{l}\text { Tipo de } \\
\text { valor }\end{array}$ & Definição \\
\hline $\begin{array}{l}\text { Valor } \\
\text { científico }\end{array}$ & $\begin{array}{l}\text { O valor científico de um local de interesse geomorfológico está associado à } \\
\text { investigação cientifica em geomorfologia, "pela quantidade e qualidade de } \\
\text { trabalhos realizados acerca desse local, através de elementos disponíveis } \\
\text { úteis a essa investigação" e “na sua potencial utilização como recurso } \\
\text { didactico, não apenas pela existência de elementos com valor científico (ou } \\
\text { outros) presentes, mas igualmente pela facilidade em demonstrar esses } \\
\text { elementos a público menos especializado". (PEREIRA, 2006, p. 67) }\end{array}$ \\
\hline $\begin{array}{l}\text { Valor } \\
\text { ecológico }\end{array}$ & $\begin{array}{l}\text { O valor ecológico de um local de interesse geomorfológico diz respeito às } \\
\text { relações entre os processos geomorfológicos e ecológicos e valoriza "o } \\
\text { facto das geoformas suportarem habitats característicos". (PEREIRA, 2006, } \\
\text { p. 69) }\end{array}$ \\
\hline $\begin{array}{l}\text { Valor } \\
\text { cultural }\end{array}$ & $\begin{array}{l}\text { O valor cultural está baseado nas relações estabelecidas entre as atividades } \\
\text { humanas e as geoformas, seja como causa, seja como consequência. Esta } \\
\text { valorização pode se dar pela "expressão artística como a pintura, a música } \\
\text { ou o cinema, em elementos etnográficos, nas várias formas de literatura, em } \\
\text { acontecimentos históricos importantes, ou de carácter religioso ou } \\
\text { mitológico". (PEREIRA, 2006, p. } 70 \text { ) }\end{array}$ \\
\hline $\begin{array}{l}\text { Valor } \\
\text { estético }\end{array}$ & $\begin{array}{l}\text { O valor estético é difícil de avaliar e quantificar, pois dependem muito do } \\
\text { observador. Porém, ela "deve considerar critérios como a dimensão das } \\
\text { geoformas, o estado de conservação, o contraste de elementos } \\
\text { geomorfológicos e de cores, e a interação com outros elementos, como a } \\
\text { vegetação ou aspectos culturais". (PEREIRA, 2006, p. 71) }\end{array}$ \\
\hline $\begin{array}{l}\text { Valor } \\
\text { econômico }\end{array}$ & $\begin{array}{l}\text { O valor econômico das geoformas depende de sua potencialidade } \\
\text { "enquanto motor de desenvolvimento econômico". Sua avaliação deve } \\
\text { considerar "critérios relacionados com suas potencialidades de uso, como } \\
\text { por exemplo, a visibilidade, a acessibilidade, a presença de água ou neve, a } \\
\text { existência de equipamentos de apoio, de iniciativas de divulgação ou ainda } \\
\text { de público potencialmente interessado". (PEREIRA, 2006, p. 72) }\end{array}$ \\
\hline
\end{tabular}

No Brasil, os temas patrimônio geológico e geomorfológico ainda são recentes e poucos são os trabalhos nessa linha de pesquisa. No entanto, para que o patrimônio geomorfológico seja mais reconhecido pela sociedade e pelos órgãos de proteção do meio ambiente são necessários estudos e o desenvolvimento de estratégias para a promoção desse patrimônio, que conforme Vieira e Cunha (2006) se iniciam pela investigação, inventariação e classificação, passando pela recuperação, proteção e conservação e por fim a divulgação, sensibilização e educação acerca do patrimônio geomorfológico. 
Duas etapas são primordiais no processo de avaliação do patrimônio geomorfológico: a inventariação e a quantificação. A inventariação conta com o conhecimento geomorfológico da área por parte do avaliador, apoiada no levantamento fotográfico, bibliográfico e trabalhos de campo, enquanto a quantificação utiliza métodos numéricos para avaliação de critérios, o que permite a comparação e definir a relevância dos locais de interesse geomorfológico.

No que tange à valoração dos elementos naturais, Pereira (2010, p. 179), afirma que é uma abordagem antropocêntrica, pois está focada na "perspectiva humana e do uso potencial dos elementos da natureza", mas ao mesmo tempo extremamente importante para a gestão territorial, pois, "através da mesma, pode-se definir quais os locais com potencial para serem alvo de iniciativas de conservação, além de se estabelecer as condições de uso dos espaços naturais".

\section{GEOCONSERVAÇÃO}

A geoconservação "tem como objetivo a conservação e gestão do patrimônio geológico e processos naturais a ele associados". (BRILHA, 2005, p. 53), em outras palavras, a geoconservação tem como objetivo principal proteger a geodiversidade, garantindo sua evolução natural.

Brilha (2005) estabeleceu algumas estratégias de geoconservação com o objetivo de conservação do patrimônio geológico, agrupadas nas etapas sequenciais: inventariação, quantificação, classificação, conservação, valorização, divulgação e monitoramento.

1. Inventariação e avaliação: a inventariação consiste na identificação e caracterização de geossítios com características geológicas excepcionais, enquanto a avaliação consiste na quantificação desses geossítios, através de critérios como, por exemplo: valor intrínseco, estético, econômico, cultural, histórico, etc., visando à seriação de todos os geossítios.

2. Classificação: é uma etapa que depende da legislação existente em cada país para a proteção e gestão do patrimônio geológico. O nível de proteção pode ser nacional, regional e local.

3. Conservação: tem o objetivo de permitir o acesso do público ao geossítio, e ao mesmo tempo, assegurar sua integridade física. 
4. Valorização e divulgação: a valorização consiste no conjunto de ações para disponibilizar informações sobre o geossítio em seu local de origem, permitindo ao público reconhecer o valor do referido geossítio, enquanto a divulgação pode ser realizada através da promoção do geossítio para a sociedade em geral (Figura 3)

5. Monitorização: consiste na avaliação periódica da relevância de um geossítio, que permite definir estratégias para que essa relevância seja mantida.

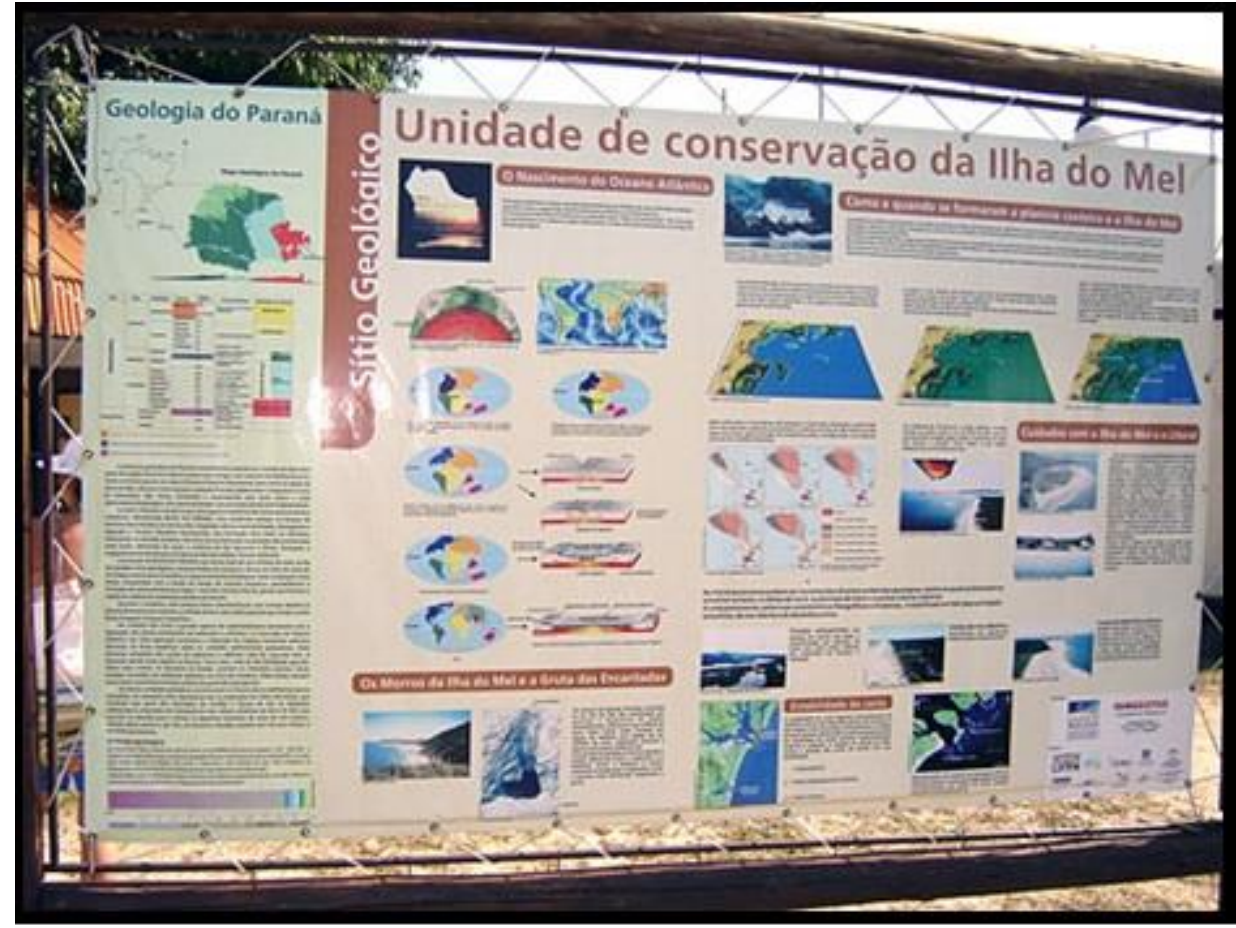

Figura 3: Exemplo de painel interpretativo da llha do Mel (PR). Fonte < http://www.trilhaseaventuras.com.br/diarioviagem/viagem.asp?id=380\&id_colunista=59>

Além das etapas descritas por Brilha (2005), também se tornam importantes a conscientização da população, das autoridades locais, educação de crianças, jovens e adultos (geoeducação), o estímulo ao turismo sustentável e, principalmente, a valorização dos costumes, atividades e produtos locais (BORBA, 2011, BENTO E RODRIGUES, 2013). 


\section{A GEOCONSERVAÇÃO EM NÍVEL INTERNACIONAL}

$\mathrm{Na}$ Europa, os estudos para o desenvolvimento e implementação de estratégias de geoconservação estão bem avançados, enquanto no Brasil a temática ainda é pouco estudada e conhecida, sendo poucos os trabalhos que abordam essa questão (LIMA, 2008).

A Convenção do Patrimônio Mundial da UNESCO em 1972 contribuiu para a proteção dos bens tanto culturais quanto naturais de valor excepcional, inestimável e insubstituível em nível internacional. Partindo do pressuposto que os patrimônios culturais e naturais estão sujeitos a ameaças de destruição e degradação, sendo bastante vulneráveis, os Estados-membros se tornaram responsáveis em "identificar, proteger, conservar, reabilitar e transmitir às futuras gerações" a relevância de tal patrimônio (LIMA, 2008, p.14).

Lima (2008), ainda afirma que, de acordo com dados da UNESCO do ano de 2008, dos 878 sítios do patrimônio cultural e natural que configuravam a Lista do Patrimônio Mundial, apenas 174 compreendiam o patrimônio natural. Esse número pode ser considerado relativamente pequeno em relação à geodiversidade do planeta.

O Projeto Geosites surge em 1996, proposto pela União Internacional de Ciências Geológicas (IUGS), com o apoio da Unesco e da Associação Europeia para a Conservação do Patrimônio Geológico (ProGEO), reunindo a comunidade geológica envolvida com a geoconservação, com objetivo de "proporcionar uma base objetiva que sirva de suporte para qualquer iniciava de âmbito nacional ou internacional para a proteção do patrimônio geológico mediante a elaboração de um inventário e base de dados de lugares de interesse geológico global” (AZEVEDO, 2007, p.37).

O método de trabalho do projeto permitia a seleção de locais significativos de interesse científico nos países "merecedores de reconhecimento internacional e proteção", através de um "método comparativo de base científica" (LIMA, 2008, p.18).

As etapas do projeto Geosites são apresentadas resumidamente, segundo Wimbledon et al. (2000 apud LIMA, 2008, p. 19):

- "Constituição de um grupo nacional; 
- Promoção da participação geral dos geólogos e de outros especialistas do país;

- Identificação das categorias temáticas de cada país, e realização de consultas com especialistas;

- Seleção dos principais sítios dentro de cada categoria temática;

- Publicação das listas de sítios e realização das consultas com especialistas;

- Revisão das listas de sítios e as categorias temáticas;

- Comparação das listas em colaboração com colegas dos países vizinhos;

- Obtenção de um equilíbrio entre as diferentes opções transfronteiriças;

- Publicação e consulta das listas regionais de sítios de interesse geológico;

- Finalização da lista;

- Documentação dos sítios selecionados e registrados em uma base de dados IUGS - Geosites".

Os critérios utilizados pelo projeto Geosites, segundo Cumbe (2007), para a seleção dos geossítios são: representatividade; ser singular ou único; possibilidade e aptidão para correlação; disponibilidade e potencialidades para a realização de estudos posteriores, reinterpretações, para a educação e cultura; complexidade e geodiversidade.

Em 2003, as atividades do grupo de trabalho sobre Geosites foram encerradas e a União Internacional de Ciências Geológicas (IUGS), desde então, concentra seus trabalhos para o público em geral e a comunidade não científica (LIMA, 2008).

Outra iniciativa na vertente da geoconservação, foi a criação, em 2004, da Rede Global de Geoparques (Global Geoparks Network - GGN), integrada por vários países tem com objetivo "promover a conservação de um ambiente são e fomentar a educação em Geociências e o desenvolvimento econômico sustentável local" (ZOUROS, 2004, apud BRILHA, 2005, p. 121).

O geoparque é definido pela UNESCO como:

um território com limites bem definidos e com uma área suficiente alargada de modo a permitir um 
desenvolvimento socioeconômico local, cultural, ambientalmente sustentável. O geoparque deverá contar com geossítios de especial relevância científica ou estética, de ocorrência rara, associado a valores arqueológicos, ecológicos histórico ou culturais. (UNESCO, apud BRILHA, 2005 p.119).

KOMOO e PATZAK (2008) apresentam um excelente trabalho sobre este tema, com uma descrição da situação dos geoparques na região leste e sudeste da Ásia, com exemplos de diversos países.

De acordo Brilha (2012, p.34) em 2012 existiam 88 geoparques distribuídos em 27 países. Os objetivos principais dos geoparques, segundo Barreto (2007, p. 33) são:

- Preservar o patrimônio geológico para as futuras gerações;

- Fazer com que a sociedade se relacione com o meio ambiente geológico, paleontológico, geomorfológico;

- Levar a humanidade a valorizar e exercitar o senso de responsabilidade para com as obras da natureza.

A Figura 4 ilustra algumas atrações contidas nos geoparques.

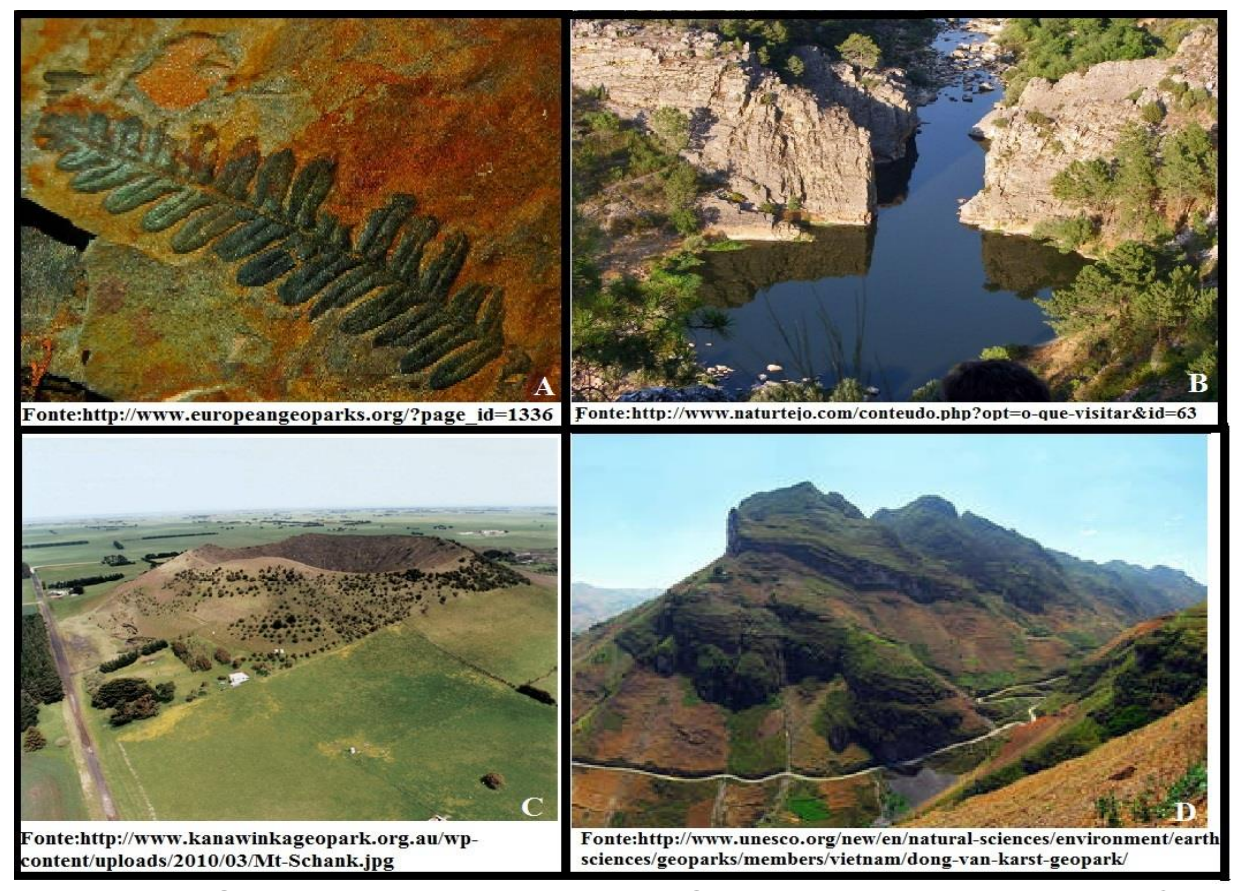

Figura 4 - Mosaico dos Geoparques mundiais - A: Samambaia fossilizada no Carnic Alps Geopark - Áustria; B: Geomonumento das Portas de Almourão no Geopark Naturtejo Portugal; C: Cratera Mount Schank no Kanawinka Geopark - Austrália; D: Planaltos no Dong Van Karst Geopark - Vietnã. Organização dos autores. 


\section{A GEOCONSERVAÇÃO NO BRASIL}

Assim como em outros países, o Brasil teve algumas iniciativas no que tange à geoconservação. Em 1997, o marco inicial sobre o patrimônio geológico brasileiro ocorreu com a criação da Comissão Brasileira dos Sítios Geológicos e Paleobiológicos (SIGEP), pelo Departamento Nacional de Produção Mineral (DNPM). A comissão foi criada, segundo Pereira (2010, p.27), para "elencar os geossítios brasileiros para a lista indicativa global de sítios geológicos (GILGES Global Indicative List of Geological Sites)". Atualmente, o SIGEP segue em atividade, divulgando através de seu site (http://sigep.cprm.gov.br/) informações sobre o inventário de sítios geológicos no país e como cadastrar novas propostas, contribuindo assim com a geoconservação.

Outro projeto importante, criado em 2006 pelo Serviço Geológico do Brasil CPRM - foi o Projeto Geoparques, que tem como "premissa básica a identificação, levantamento, descrição, diagnóstico e ampla divulgação de áreas com potencial para futuros geoparques no território nacional, bem como o inventário e quantificação de geossítios" (BRILHA, 2012), tendo em vista dois fatores importantes, a grande geodiversidade nacional e a extensão territorial.

Em 2006, no estado do Ceará, foi aprovado segundo os critérios definidos pela Rede Global de Geoparques, o primeiro Geoparque das Américas, o Geopark Araripe, localizado ao sul do estado, na região do Cariri. O Geoparque abrange uma área de 5 mil quilômetros quadrados e até o momento, apresenta nove sítios geológicos de grande importância científica, com estratos geológicos e formações fossilíferas, "que permitem a compreensão de parte da história da evolução da vida e do planeta Terra, no Período Cretáceo" (LIMA, 2008, p. 40).

Devido a grande geodiversidade aliada a extensão territorial do Brasil, a CPRM apresenta áreas de potenciais geoparques, como pode ser visualizado no Quadro 3. Existem ainda algumas propostas que estão em avaliação e outras ainda passarão por avaliações futuras.

Quadro 3: Relação de propostas do Projeto Geoparques para o período 2009-2010. Fonte: Schobbenhaus e Silva, 2010, p. 12. 


\begin{tabular}{|c|c|c|}
\hline Potencial área & UF & Tipo de interesse \\
\hline $\begin{array}{l}\text { Quadrilátero } \\
\text { Ferrífero }\end{array}$ & MG & $\begin{array}{l}\text { Estratigráfico, paleoambiental, história da mineração, } \\
\text { geomorfológico, metalogenético. }\end{array}$ \\
\hline Morro do Chapéu & BA & Estratigráfico, geomorfológico, histórico. \\
\hline Catimbau & PE & Ambiental, arqueológico, geomorfológico. \\
\hline $\begin{array}{l}\text { Fernando de } \\
\text { Noronha }\end{array}$ & PE & Ígneo, beleza cênica. \\
\hline Sete Cidades & PE & Geomorfológico, paleoambiental. \\
\hline Pirineus & GO & Estratigráfico, tectônico, geomorfológico, histórico-cultural. \\
\hline Quarta Colônia & RS & Paleontológico (tetrápodes), estratigráfico. \\
\hline $\begin{array}{l}\text { Alto Vale do } \\
\text { Ribeira }\end{array}$ & SP/PR & Espeleológico, paleoambiental \\
\hline Serra da Capivara & $\mathrm{PI}$ & Estratigráfico, arqueológico \\
\hline $\begin{array}{l}\text { Chapada } \\
\text { Diamantina } \\
\text { Oriental }\end{array}$ & BA & Geomorfológico, paleoambiental, beleza cênica, histórico-cultural. \\
\hline Rio de Contas & BA & Estratigráfico, geomorfológico, histórico. \\
\hline $\begin{array}{l}\text { Cachoeiras do } \\
\text { Amazonas }\end{array}$ & AM & Estratigráfico, espeleológico, arqueológico. \\
\hline $\begin{array}{l}\text { Astroblema } \\
\text { Araguainha- } \\
\text { Ponte Branca }\end{array}$ & MT/GO & Astroblema (estrutura de impacto de meteorito). \\
\hline $\begin{array}{l}\text { Chapada dos } \\
\text { Guimarães }\end{array}$ & MT & Geomorfológico, paleontológico, espeleológico, beleza cênica. \\
\hline $\begin{array}{l}\text { Bodoquena- } \\
\text { Pantanal }\end{array}$ & MS & $\begin{array}{l}\text { Espeleológico, paleoambiental, geomorfológico, paleontológico, } \\
\text { metalogenético. }\end{array}$ \\
\hline Cânions do Sul & $\mathrm{RS} / \mathrm{SC}$ & Beleza cênica, geomorfológico, ígneo. \\
\hline Serra da Canastra & MG & Beleza cênica, geomorfológico. \\
\hline Seridó & PE & $\begin{array}{l}\text { Estratigráfico, ígneo, geomorfológico, metalogenético, histórico- } \\
\text { cultural. }\end{array}$ \\
\hline Peirópolis & MG & Paleontológico (dinossauros) \\
\hline Monte Alegre & PA & Estratigráfico, geomorfológico, tectônico, arqueológico. \\
\hline $\begin{array}{l}\text { Alto Alegre dos } \\
\text { Parecís }\end{array}$ & $\mathrm{RO}$ & Estratigráfico, geomorfológico, beleza cênica. \\
\hline $\begin{array}{l}\text { Cabo de Santo } \\
\text { Agostinho }\end{array}$ & PE & Ígneo, estratigráfico, beleza cênica, histórico-cultural. \\
\hline
\end{tabular}


No que se refere à legislação, no ano de 2000, foi instituído com a lei 9.985, o Sistema Nacional de Unidades de Conservação- SNUC, que possui como objetivos "proteger as características relevantes de natureza geológica, geomorfológica, espeleológica, arqueológica, paleontológica e cultural” nas áreas protegidas e "proteger e recuperar recursos hídricos e edáficos" (LEI 9.985/2000, Art.4º, inciso VII e VIII). No entanto, a criação do SNUC teve o foco na proteção da biodiversidade, não estabelecendo nenhuma unidade de proteção especificamente para os geossítios, ou seja, a geodiversidade muitas é vezes protegida em segundo plano nas unidades de conservação.

\section{CONCLUSÕES}

A extensão territorial do país confere ao Brasil um arcabouço geológico e geomorfológico diversificado, o que consequentemente resulta numa alta geodiversidade. No entanto, os estudos relacionados à geomorfologia no país ainda não consideram as questões sobre o patrimônio geomorfológico, ficando esse assunto restrito a trabalhos pontuais, muitas vezes tratando o patrimônio geológico como assunto principal. Percebe-se a necessidade do envolvimento da comunidade geomorfológica nos estudos sobre o patrimônio geomorfológico, pois dessa forma metodologias de inventariação e quantificação desse patrimônio podem ser desenvolvidas, estratégias efetivas de proteção, conservação, divulgação e valorização podem ser criadas e uma legislação específica para proteção dos geomorfossítios pode ser desenvolvida.

As estratégias de geoconservação, graças aos esforços do Serviço Geológico Brasileiro e do Departamento Nacional de Produção Mineral estão avançadas, porém se concentram no âmbito do patrimônio geológico. A criação do Geopark Araripe foi um marco para a geoconservação brasileira, pois é o primeiro geoparque na América do Sul. Os congressos nacionais e regionais de geologia estão inserindo em suas discussões eixos temáticos sobre 0 trinômio geodiversidade, geoconservação e geoturismo, porém, torna-se necessário inserir nesse contexto as discussões sobre o patrimônio geomorfológico e expandir os grupos de trabalho para os encontros de geomorfologia e ciências afins. 
A geomorfologia como uma ciência que estuda as formas de relevo, deve inserir em suas discussões e pesquisas a temática do patrimônio geomorfológico, para que estudos sobre metodologias, inventariação e quantificação sejam desenvolvidos e com isso Brasil possa ser inserido e consolidado em grupos de trabalho sobre geodiversidade, geoconservação e geopatrimônio em nível mundial.

Agradecimentos: A CAPES - Coordenação de Aperfeiçoamento de Pessoal de Nível Superior pela bolsa de doutorado concedida.

\section{REFERÊNCIAS}

AZEVEDO, U. R. Patrimônio geológico e geoconservação no Quadrilátero Ferrífero, Minas Gerais: Potencial para a criação de um Geoparque da Unesco. 2007. 211 f. Tese (Doutorado em Geologia) - Universidade Federal de Minas Gerais, Belo Horizonte, $2007 . \quad$ Disponível em: <http://www.bibliotecadigital.ufmg.br/dspace/bitstream/handle/1843/MPBB76LHEJ/tese ursula ruchkys.pdf?sequence=1 > Acesso em: fev. 2012.

BARRETO, J. M. C. Potencial Geoturístico da Região de Rio de Contas- BahiaBrasil. 2007. 164 f. Dissertação (Mestrado em Geologia)- Universidade Federal da Bahia. Salvador/Bahia- Brasil, 2007. Disponível em: <http://www.geoturismobrasil.com/artigos/Disserta\%C3\%A7\%C3\%A30\%20Jos\%C3 \%A9\%20Marden\%20Barreto 2007.pdf> Acesso em: fev. 2012.

BENTO, L. C. M.;RODRIGUES, S. C. Geodiversidade e potencial Geoturístico do Salto de Furnas - Indianópolis-MG. RA'E GA, v.21, p.272-297, 2011. . Disponível em: < http://ojs.c3sl.ufpr.br/ojs2/index.php/raega/article/view/21246>Acesso em: out. 2013.

BENTO, L. C. M.;RODRIGUES, S.C. Geoturismo em unidades de conservação: uma nova tendência ou uma necessidade real? - Estado da arte. Revista do Departamento de Geografia - USP, v. 25, p. 77-97, 2013. Disponível em: < http://citrus.uspnet.usp.br/rdg/ojs/index.php/rdg/article/view/440 > Acesso em: out. 2013.

BORBA, A. W. Geodiversidade e geopatrimônio como bases para estratégias de geoconservação: conceitos, abordagens, métodos de avaliação e aplicabilidade no contexto do Estado do Rio Grande do Sul. Revista Pesquisa em Geociências, v.38, ํ.1; p.3-14, jan/abr. 2011. Disponível em: $<$ http://www.pesquisasemgeociencias.ufrgs.br/3801/01-3801.pdf $>$. Acesso em: fev. 2012.

BRASIL. Lei Federal no 9985 de 18 de julho de 2000. "Institui o Sistema Nacional de Unidades de Conservação da Natureza e dá outras providências". Presidência da 
República - Casa Civil, Brasília, DF, 18 jul. 2000. Disponível em: <http://www.planalto.gov.br/CCIVIL/Leis/L9985.htm>. Acesso em: fev. 2012.

BRILHA, J. Rede Global de Geoparques Nacionais: Um instrumento para a promoção Internacional da Geoconservação. In: SCHOBBENHAUS, C.; SILVA, C. J.(org).Geoparques do Brasil : propostas. Rio de Janeiro: CPRM, 2012. v. 1, p.2938

BRILHA, J.B.R. Patrimônio geológico e geoconservação: a conservação da natureza na sua vertente geológica. Braga: Palimage, 2005.190 p. Disponível em:< http://www.dct.uminho.pt/docentes/pdfs/jb livro.pdf > Acesso em: fev. 2012.

BUREK,C. The role of LGAPs (local Geodiversity Action Plans) and Welsh RIGS as Local Drivers for Geoconservation within Geoturism in Wales. Geoheritage, v. 4, p.45-63, 2012. Disponível em: < http://link.springer.com/article/10.1007\%2Fs12371012-0054-4 > Acesso em: out. 2013.

CUMBE, A. N. F. O patrimônio geológico de Moçambique: proposta de metodologia de inventariação, caracterização e avaliação. 2007. 273 f. Dissertação (Mestrado em Patrimônio Geológico e Geoconservação) - Departamento de Ciências da Terra, Universidade do Minho, Braga, 2007. Disponível em:< http://www.repositorium.sdum.uminho.pt> Acesso em: fev. 2012.

GRAY, M. Geodiversity and Geoconservation: what, why, and how? Geodiversity \& Geoconservation, p. 4-12, 2005. Disponível em: < http://www.georgewright.org/223gray.pdf>. Acesso em: ago. 2012.

HJORT, J. LUOTO, M. Geodiversity of high-latitude landscapes in northern Finland. Geomorphology. v. 115, p. 109-116, 2010. Disponível em: < http://www.sciencedirect.com/science/article/pii/S0169555X09004140 > Acesso em: out. 2013.

KOMOO, I. E. ; PATZAK, M. Global Geoparks Network: An Integrated approach for Heritage Conservation and ustainable Use. In: LEMAN, M.S; REEDMAN, A, PEI, C.S. Geoheritage of East and Southeast Asia, Ampang Press. Kuala Lampur. Malaysia. 2008, p. 3-13.

LIMA, F. F. Proposta metodológica para a inventariação do patrimônio geológico brasileiro. 2008. 103 f. Dissertação (Mestrado em Patrimônio Geológico e Geoconservação). Escola de Ciências. Universidade do Minho. Portugal, 2008. Disponível em < http://www.dct.uminho.pt/mest/pgg/docs/tese lima.pdf Acesso em: fev.2012.

LOPES, L.S.O. ARAUJO, J. L.L. Princípios e estratégias de geoconservação. Observatorium: Revista Eletrônica de Geografia, v.3, n.7, p. 66-78, out. 2011. Disponível em < http://www.observatorium.ig.ufu.br/pdfs/3edicao/n7/5.pdf $>$. Acesso em: fev.2012. 
NASCIMENTO, M. A. ; RUCHKYS, U. A. de; MANTESSO NETO, V. Geodiversidade, geoconservação e geoturismo - trinômio importante para a proteção do patrimônio geológico. São Paulo: Sociedade Brasileira de Geologia, 2008.

PANIZZA, M. Geomorphosites: concepts, methods and examples of geomorphological survey. Chinese Science Bulletin. n.46,. vol. 4-6. p.4-5. Dez/2001.

PEREIRA, D.I.; PEREIRA, P. BRILHA, J. SANTOS, L. Geodiversity Assessment of Parana State (Brazil): An Innovative Approach. Environmental Management, v.52, p.541-522, 2013.2 Disponível em < http://link.springer.com/article/10.1007\%2Fs00267-013-0100-2 > Acesso em: out. 2013.

PEREIRA, P. J. da S. Patrimônio geomorfológico: conceptualização, avaliação e divulgação. Aplicação ao Parque Nacional de Montesinho. 2006, 395f. Tese. (Doutorado em Ciências - Geologia). Universidade do Minho. Portugal, 2006. Disponível em < http://repositorium.sdum.uminho.pt/handle/1822/6736>. Acesso em: fev.2012.

PEREIRA, R. G. F. A. Geoconservação e desenvolvimento sustentável na Chapada Diamantina (Bahia - Brasil). 2010. 295 f. Tese (Doutoramento em Ciências) Universidade do Minho, Portugal, 2010. Disponível em:< http://repositorium.sdum.uminho.pt/handle/1822/10879 >. Acesso em: out. 2012.

PERKINS, H.E. Measuring love and care for nature. Journal of Environmental Psychology, v. 30, p.455-463, 2010. Disponível em: < http://www.sciencedirect.com/science/article/pii/S0272494410000551> Acesso em: out. 2013.

ProGEO, 2011: Conserving our shared geoheritage - a protocol on geoconservation principles, sustainable site use, management, fieldwork, fossil and mineral collecting.10 p. 2011.Disponível em:< http://www.progeo.se/progeo-protocoldefinitions-20110915.pdf>. Acesso em: out. 2012.

REYNARD, E.; CORATZA, P. Working Group on Geomorphosites: research, assessment and improvement, [20--]. Disponível em: < http://www.geomorph.org/wg/wggs.html>. Acesso em: out. 2012.

RODRIGUES, M.; FONSECA, A. A Valorização do Geopatrimónio no Desenvolvimento Sustentável de Áreas Rurais. Colóquio Ibérico de Estudos Rurais, - Cultura Inovação e Território, Coimbra. 2008. P.1-14. Disponível em: < http://www.sper.pt/actas7cier/PFD/Tema\%20ll/2 14.pdf>. Acesso em: out. 2012.

RODRIGUES, S.C.; SILVA, T.I. Dam construction and loss of geodiversity in the Araguari River Basin, Brazil. Land Degradation Development, v.23, p.419-426, 2012. 
RODRIGUES, S.C.PEDROSA, A.S. Analise da perda de Geodiversidade (Patrimônio Geomorfológico) em função da construção de barragens. In: RODRIGUES, S.C.; MERCANTE, M. A. (org). Avaliação sócio-ambiental do domínio dos cerrados e pantanal: métodos e técnicas. Uberlândia: UFU; Campo Grande: AnhangueraUniderp, 2013, p.7-22.

RUBAN D.A. Quantification of geodiversity and its loss. Proceedings of the Geologists' Association, v.121, p. 326-333, 2003. Disponível em: < http://www.sciencedirect.com/science/article/pii/S0016787810000556 > Acesso em: out. 2013.

RUBAN, D. A. How diverse should be geodiversity? Reply to Knight "Evaluating geological heritage". Proceedings of the geologists' Association, v. 122, p.511513, 2011. Disponível em: < http://www.sciencedirect.com/science/article/pii/S0016787810001380 > Acesso em: out. 2013.

SCHOBBENHAUS, C. ; SILVA, C.R. . O papel indutor do Serviço Geológico do Brasil na criação de geoparques. Anais do Fórum do Patrimônio Cultural. Painel: Paisagem Cultural e Patrimônio Natural: Conceitos e Aplicabilidade. IPHAN, Ouro Preto, 2010, 23p. 2 Disponível em:< http://sigep.cprm.gov.br/destaques/Schobbenhaus Silva 2010.pdf >. Acesso em: fev.2012.

STANLEY, M. Geodiversity, Earth Heritage, № 14 p. 15-18, 2000.

UNESCO. Convenção para a protecção do património mundial, cultural e natural. 1972, 20 p. Disponível em < http://whc.unesco.org/archive/conventionpt.pdf>. Acesso em: fev.2012.

VIEIRA, A.; CUNHA, L. Património geomorfológico - de conceito a projecto. O Maciço de Sicó. Publicações da Associação Portuguesa de Geomorfólogos, Vol. 3, APGeom, 2006, p. 147-153. Disponível em < http://oficinaexperimental.wikispaces.com/file/view/geomorfologia sico.pdf>. Acesso em: fev.2012. 